\title{
PULMONARY EDEMA TREATED BY ARTIFICIAL RESPIRATION
}

\author{
REPORT OF A CASE * \\ THEODORE B. BARRINGER, JR., M.D. \\ NEW YORK
}

Several weeks after seeing Dr. Emerson's experiment, in the spring of 1908 , and realizing the lesson it taught in clinical therapeutics, I was called to one of my patients, whom I found in an attack of acute cardiac insufficiency. A report of this case follows:

History.-The patient, a housewife, aged 47, multipara, had had scarlet fever and chorea when a child, and a severe attack of inflammatory rheumatism in 1895 . She had had dyspnea on exertion for the last three or four years, and five or six attacks of cardiac insufficiency during this time. The chief symptoms were rapid heart action, dyspnea, cyanosis and occasionally hemoptysis. None of them was severe, and they lasted, as a rule, not over four or five hours.

Examination.--The patient was 5 feet 4 inches tall and weighed 150 pounds. The apex of the heart was in the fifth space, $4 \frac{1}{2}$ inches out; there was a marked right heart hypertrophy, and at the apex a loud presystolic crescendo murmur and a faint systolic murmur transmitted to the left. The lungs were negative; the urine negative, except for an occasional hyaline cast. At the time of my emergency call I found the patient sitting up in bed, cyanosed, very dyspneic and restless, with a tracheal rattle and a pulse 132 to the minute, quite irregular and of low tension. The heart showed a diastolic rumble instead of the usual presystolic crescendo murmur. The lungs showed quantities of moist râles which extended as high as the third or fourth ribs in front.

Treatment.-My patient evidently was suffering from an auricular paralysis. I opened the window, put an inverted chair with a pillow on it behind her back and gave her hypodermic injections of tincture of digitalis, strychnin and morphin. Then, with the husband's aid, I carried out artificial respiration. Wv raised and lowered the arms slowly ten or twelve times, then stopped for a few moments, because it tired the patient, and then resumed the movements. After a few arm movements she coughed and raised several large mouthfuls of pink, frothy sputum, and this expectoration was repeated a number of times. Between the periods of artificial respiration the tracheal rattle would continue and nothing would be expectorated. At the end of an hour the artificial respiration was stopped and the hypodermic stimulation repeated. The rattling in the throat had now ceased, the moist râles in the lungs had become much less numerous and the pulse was 118 per minute.

In two or three days the patient had entirely recovered.

The cause of the cardiac insufficiency and pulmonary edema in this case was, of course, different from that in Dr. Emerson's animal experi-

*Read at a meeting of the Section on Medicine of the New York Academy of Nedicine, March 16, 1909. 
ments. The pathology of acute cardiac failures in these cases of mitral valve lesions is probably as follows: Some overexertion, mental o: physical, interferes with what Mackenzie calls the tonicity of the right ventricle, and it dilates; tricuspid regurgitation ensues; the right auricle dilates and auricular paralysis follows. The right-heart failure is evinced clinically by the marked cyanosis, the dyspnea, the irregular rhythm, and the pulmonary edema.

My patient would very possibly have recovered if nothing had been done for her, although this was the severest attack she had ever had. The hypodermic stimulation was naturally of much help to the right heart, but I feel that the artificial respiration also aided very materially the pulmonary circulation in the way Dr. Emerson has described. Certainly the lungs were relieved of much of the transudate. This was one of the few times I have seen the typical sputum of pulmonary edema as described in the text-books.

It is interesting to note what Mackenzie says, in his recent book on diseases of the heart, about the treatment of pulmonary edema:

When, howerer, the right ventricle is enfeebled, the assistance of the respiratory movements becomes necessary. An important part can be played, in suitable cases, by placing the patient in a position to breathe freely, avoiding the restraint exerted by pressure on the ribs, and by making the patient inspire deeply.

In the Presbyterian Hospital (New York) Medical and Surgical Report for 189\%, Norton reported a case of carbolic-acid poisoning treated with the Fell-O'Dywer forced respiration apparatus. The pulmonary edema which ensued was cleared up rapidly by the artificial respiration. In this case the pulmonary circulation was aided by a rhythmical positive pressure, instead of by a rhythmical negative pressure, as in my case.

34 West Fighty-fourth Street. 